\title{
Gastrointestinal metastasis of primary lung cancer: An analysis of 366 cases
}

\author{
YUE HU $^{1}$, NOAH FEIT ${ }^{2}$, YANQIN HUANG $^{3}$, WENHONG XU $^{4}$, SHU ZHENG $^{1,3}$ and XIUZHEN LI ${ }^{5}$ \\ ${ }^{1}$ Department of Surgical Oncology, The Second Affiliated Hospital of Zhejiang University, School of Medicine, Hangzhou, \\ Zhejiang 310009, P.R. China; ${ }^{2}$ The Johns Hopkins University, Baltimore, MD 21231, USA; ${ }^{3}$ Cancer Institute; \\ Departments of ${ }^{4}$ Radiation Oncology and ${ }^{5}$ Pathology, The Second Affiliated Hospital of Zhejiang University, \\ School of Medicine, Hangzhou, Zhejiang 310009, P.R. China
}

Received August 11, 2016; Accepted September 1, 2017

DOI: $10.3892 / \mathrm{ol} .2018 .8575$

\begin{abstract}
The gastrointestinal (GI) tract is not a common site of metastasis in primary lung cancer. The aim of the present study was to reveal the clinical and prognostic characteristics of gastrointestinal metastases of lung cancer (GMLC). Information on 366 cases of GMLC was collected and factors that affect severe GI complications were analyzed. Univariate and multivariate survival analyses were performed using the Cox proportional hazards model. Of the cases analyzed, the small intestine $(59.6 \%)$ and colorectum $(25.6 \%)$ were the two organs where lung cancer was most likely to metastasize in the GI tract. Squamous cell carcinoma (28.5\%), adenocarcinoma $(27.6 \%)$ and large cell carcinoma $(20.9 \%)$ were the three most common histological types. However, compared with the histological distributions of primary lung cancer, patients with large cell carcinoma exhibited the highest elevated risk of GMLC [relative risk (RR), 4.07; $\mathrm{P}<0.001$ ] and those with adenocarcinoma exhibited the lowest risk ( RR, 0.58; $\mathrm{P}<0.001)$. Differences in organ involvement and in histological type led to varying GI complications. It was also indicated that chemotherapy was associated with a decreased risk of hemorrhage $(\mathrm{P}=0.006)$, but there was no reduction in the risk of hemorrhage associated with perforation and obstruction ( $\mathrm{P}>0.05)$. The median overall survival time of GMLC patients was 2.8 months (range, 0-108 months). The survival analyses revealed that perforation and extra-GI metastasis were negative prognostic factors but abdominal surgery was identified a
\end{abstract}

Correspondence to: Dr Yue Hu, Department of Surgical Oncology, The Second Affiliated Hospital of Zhejiang University, School of Medicine, 88 Jiefang Road, Hangzhou, Zhejiang 310009, P.R. China E-mail: huyuezju@zju.edu.cn

Dr Xiuzhen Li, Department of Pathology, The Second Affiliated Hospital of Zhejiang University, School of Medicine, 88 Jiefang Road, Hangzhou, Zhejiang 310009, P.R. China

E-mail: louiehero@hotmail.com

Key words: gastrointestinal neoplasm, lung cancer, metastasis, complication, prognosis positive prognostic factor. In conclusion, the histological distribution of GMLC differed from that of primary lung cancer. Sufficient and careful patient evaluation, targeted surgeries and systemic therapies for specific patients are able to increase patient survival rate and improve the quality of life.

\section{Introduction}

As a common cancer and the leading cause of cancer-associated mortality, lung cancer has always been universally associated with poor patient prognosis (1). The incidence and mortality rates of lung cancer occupy the first or second position in malignant tumors in China and the United States (2,3). Until 2015 , the 5-year total survival rate for lung cancer was $\leq 20 \%$ in developed and developing countries (4). Between 40 and 50\% of patients present with distant metastases upon diagnosis with lung cancer have a poor 5-year survival rate of $<5 \%$ (1). Small cell lung cancer accounts for only $10 \%$ of lung cancer but non-small cell lung cancer accounts for $\sim 90 \%$, including squamous cell carcinoma, adenocarcinoma, large cell carcinoma, adenosquamous carcinoma and sarcomatoid carcinoma (4).

As demonstrated in autopsy studies, lung cancer metastases may be identified in every organ system (4). However, the gastrointestinal (GI) tract is not a common site of metastasis for primary lung cancer when compared with other sites, including bone, brain, liver and adrenal glands (5). Gastrointestinal metastases of lung cancer (GMLC) was caused by hematogenous spread and occurred at the end-stage of lung cancer. The incidence of GMLC was $<2 \%$ in clinical studies, which was much lower compared with its prevalence identified during autopsies (5-8). In previous studies, GMLC was described primarily in case reports. Systemic survival analyses and association between clinicopathological factors, therapeutic factors and GI complications were seldom discussed. The present study reviewed $>130$ studies from the last 50 years and analyzed 366 cases of GMLC to reveal its clinical and prognostic characteristics by univariate and multivariate survival analyses.

\section{Patients and methods}

Patients. A total of 33 cases of GMLC from 32 Chinese articles $(9-40)$ and 3 cases from the School of Medicine, Second 
Affiliated Hospital of Zhejiang University (Hangzhou, China). The 3 cases were presented to the hospital between 2008 and 2015 were collected in the present study. The Chinese literature was obtained from the VIP Journal Integration Platform (Chongqing, China; http://lib.cqvip.com/) published between 1993 and 2013. A total of 95 articles (5,8,41-133) from the PubMed database from 1961 to 2013 were reviewed, and 330 cases of GMLC were included. In all 366 cases of GMLC assessed, demographic and clinicopathological information was recorded and reviewed, including ethnicity, sex, age, pathology, initial lung cancer stage and therapy, interval between lung cancer diagnosis and identification of GMLC, clinical presentation, location, diameter and number of gross metastases, other metastatic site locations at the time of GMLC, GI surgeries, survival information and immunohistochemical information.

Disease classification. The histological classification of primary lung cancer was performed according to the 2004 World Health Organization classification system of lung tumors (134). The Tumor-Node-Metastasis staging was performed according to the 7th edition of the 2010 American Joint Committee on Cancer Staging manual (135). The histological distribution data of primary lung cancer was acquired from the International Lung Cancer Consortium (136).

Statistical analysis. $\chi^{2}$ test and Fisher's exact test were used to compare the incidence rates of different groups. Overall survival (OS) time was measured from the date of GMLC diagnosis to the date of mortality. This end point was computed using the Kaplan-Meier product limit method and the groups were compared using the log-rank test. Univariate and multivariate analyses of OS time were performed using Cox proportional hazards model. Only the variables with $\mathrm{P}<0.25$ in the univariate analysis were included in the multivariate analysis model and, the backward sequencing method was used (137). The variables in the univariate and multivariate analyses included region (Asia vs. The Americas vs. Europe), histological type of lung cancer (squamous cell carcinoma vs. adenocarcinoma vs. large cell carcinoma vs. small cell lung cancer vs. adenosquamous carcinoma vs. sarcomatoid carcinoma), time (synchronous vs. metachronous), number (solitary vs. multiple), the organ where metastasis has been identified (esophagus vs. stomach vs. small intestine vs. colorectum vs. multiple organs), extra-GI metastasis (yes vs. no), perforation (yes vs. no), surgery of primary lung cancer (yes vs. no) and abdominal surgery (yes vs. no). Metastasis was considered synchronous if the interval of diagnosis between lung cancer and GI metastasis was $<1$ month. Metastasis was considered metachronous if the interval was $>1$ month. $\mathrm{P}<0.05$ (two-sided) was considered statistically significant. The statistical analyses were performed using SPSS Statistics software (version 19.0; IBM Corp., Armonk, NY, USA).

\section{Results}

Patient and tumor characteristics. As presented in Table I, the majority of the patients were from Asia (62.3\%) and $>80 \%$ of them were male. The three countries with the greatest number of patients analyzed were Japan (139 cases), China (65 cases) and the United States (64 cases). The median age was 63 years (range, 31-92 years). The small intestine was the most frequently involved organ (59.6\%) in the GI tract, and the colorectum ranked second $(25.6 \%)$. Of the small intestine cases of GMLC, where the site of metastasis was specific, the majority of cases $(63.4 \%)$ occurred in the jejunum. GI perforation $(42.0 \%)$, hemorrhage $(24.6 \%)$ and obstruction $(20.4 \%)$ were the three most common complications. Synchronous and metachronous metastases were similarly probable (46.2\% vs. $53.8 \%$ ). The median time of metachronous patients from primary cancer diagnosis to GI metastasis was 6 months (range, 1-108 months). Solitary GMLCs were present in an increased number of patients compared with multiple metastases (69.4\% vs. 30.6\%). Furthermore, extra-GI metastases were present in the majority of patients $(70.5 \%)$. The liver, brain, bone and adrenal gland were the four most prevalent sites of metastasis (data not shown), which was expected. In total, $\sim 1 / 3$ of the patients $(33.3 \%)$ underwent surgical resection to remove the primary cancer and surgeries were performed in the GI tract in $75.8 \%$ of patients. Partial gastrectomy and enterectomy were the main types of abdominal resections performed (86.5\%). These statistics are based solely upon cases where data was available.

Squamous cell carcinoma (28.5\%), adenocarcinoma (27.6\%) and large cell carcinoma (20.9\%) were the three most common histological types of GMLC. When the histological distributions between GMLC and primary lung cancer were compared, it was observed that there was an increased frequency of GMLC of large cell carcinoma, small cell lung cancer and squamous cell carcinoma compared with GMLC of adenocarcinoma and other types of cancer $(\mathrm{P}<0.01$; Table II).

Complications. The association between involved organs, histological type and GI complications is presented in Table III. Perforation of the small intestine (63.7\%) occurred more frequently compared with perforation of stomach and colorectum $(\mathrm{P}<0.001)$. The organs at risk of hemorrhage, from most to least common, were the stomach, colorectum and small intestine ( $\mathrm{P}<0.05$ in comparisons between two organs). No obstruction occurred in all 36 patients with gastric metastasis, and the incidence of obstruction was much lower compared with colorectum $(\mathrm{P}=0.003)$ or small intestine $(\mathrm{P}=0.003)$. In all the histological types of lung cancer analyzed, sarcomatoid carcinoma exhibited the lowest likelihood of perforation and the greatest likelihood of hemorrhage $(\mathrm{P}<0.05)$. The risks of perforation of squamous cell carcinoma and small cell lung cancer were increased compared with the risks associated with adenocarcinoma $(\mathrm{P}<0.05)$. The risks of hemorrhage of squamous cell carcinoma and small cell lung cancer were lower compared with the risks for large cell carcinoma $(\mathrm{P}<0.05)$. No statistically significant difference was observed between two other organs or histological types $(\mathrm{P}>0.05)$. No significant association was identified between histological type and GI obstruction ( $\mathrm{P}>0.05)$.

The association between GI complications and chemotherapy is indicated in Table IV. In total, $1 / 4(26.5 \%, 97 / 366)$ of the cases analyzed contained patient data of chemotherapy. Hemorrhage was more common in patients with GMLC who received no chemotherapy $(\mathrm{P}=0.006)$. There was no significant 
Table I. Patient, tumor and treatment characteristics of 366 cases of gastrointestinal metastases of lung cancer.

A, Demographic factors

\begin{tabular}{lcc}
\hline Characteristics & Patients, $n$ & Percentage \\
\hline Region & & \\
Asia & 228 & 62.3 \\
America & 67 & 18.3 \\
Europe & 71 & 19.4 \\
Sex (not reported in 114 cases) & & \\
Male & 208 & 82.5 \\
Female & 44 & 17.5 \\
Age, years (not reported in 13 cases) & & \\
554 & 54 & 15.3 \\
$55-64$ & 133 & 37.7 \\
$65-74$ & 116 & 32.9 \\
$\geq 75$ & 50 & 14.2 \\
\hline
\end{tabular}

B, Tumor factors

\begin{tabular}{l} 
Characteristics \\
\hline Involved organ \\
(not reported in 10 cases) \\
Esophagus \\
Stomach \\
Small intestine ${ }^{\mathrm{a}}$ \\
Colorectum \\
Multiple organs \\
Complications (not reported in 9 cases) \\
Perforation \\
Hemorrhage \\
Obstruction \\
Histological type \\
(not reported in 22 cases) \\
Small cell lung cancer \\
Squamous cell carcinoma \\
Adenocarcinoma \\
Large cell carcinoma \\
Sarcomatoid carcinoma \\
Adenosquamous carcinoma \\
Other types
\end{tabular}

Patients, $n$ Percentage

Synchronous or metachronous metastasis (not reported in 208 cases)

Synchronous

Metachronous

Number of GI metastasis

(not reported in 268 cases)

Solitary

Multiple

Extra-GI metastasis

(not reported in 220 cases)

No

Yes
Table I. Continued.

C, Treatment factors

Treatment

Patients, $n$ Percentage

Lung cancer surgery

(not reported in 234 cases)

No

88

66.7

Yes

Abdominal surgery

(not reported in 180 cases)

No

45

24.2

$\mathrm{Yes}^{\mathrm{c}}$

141

75.8

${ }^{a}$ Metastasis in the small intestine: Duodenum, 19 cases; jejunum, 104 cases; ileum, 41 cases; not otherwise specified, 60 cases. ${ }^{b}$ Metastasis in the colorectum: Appendix and ileocecus, 10 cases; colon,

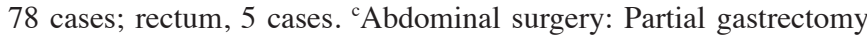
and enterectomy, 122 cases; gastrointestinal fistula, bypass surgery and repair of the perforation, 7 cases; not otherwise specified, 12 cases.

difference in the risks of perforation and obstruction between patients who had received and had not received chemotherapy $(\mathrm{P}>0.05)$.

Immunohistochemical analysis. In total, there were 35 cases for which immunohistochemical data were available. Information from this limited number of cases illustrated that a typical immunohistochemical staining of GMLC was positive for thyroid transcription factor-1 (TTF-1; 84.4\%, 27/32) and cytokeratin 7 (CK7, 96.6\%, 28/29), but negative for CK20 (96.6\%, 28/29) and caudal-related homeodomain transcription 2 (CDX2, 100\%, 23/23).

Survival estimates. Survival rate data was available for 268 of the 366 patients studied. A total of 246 patients had succumbed to disease by the end of the duration of the study, and the data of the other 22 patients were censored data. The median OS time was 2.8 months (range, 0-108 months, Fig. 1A). Univariate Cox analysis (Table V) revealed that patients from the Americas exhibited poorer prognoses compared with patients from Asia $(\mathrm{P}<0.001)$. It was also indicated that the survival rates for patients with small cell lung cancer and sarcomatoid carcinoma were increased compared with patients with squamous cell carcinoma (unadjusted hazard ratios (HRs), $0.62(\mathrm{P}=0.03)$ and 0.34 ( $\mathrm{P}=0.005)$, respectively). The other prognostic factors, which indicate a poor survival outcome, included synchronous metastasis, perforation of GMLC, extra-GI metastasis and lack of abdominal surgery $(\mathrm{P}<0.05)$. Patients with multiple metastases exhibited marginal poorer prognoses compared with patients with solitary metastases $(\mathrm{P}=0.06)$. There were no statistical significance between overall survival rate and other factors, (sex, age, organs of GI metastasis, and surgery on the primary lung cancer) $(\mathrm{P}>0.05)$.

In multivariate analysis, following adjustment for prognostic factors, the region where the patients were from, 
Table II. Comparison of the histological distributions between gastrointestinal metastases of lung cancer and primary lung cancer.

\begin{tabular}{|c|c|c|c|c|c|}
\hline Histological type & GMLC, $\%$ & Primary lung cancer, $\%^{a}$ & $\chi^{2}$-value & P-value & RR $(95 \%$ CI $)$ \\
\hline Small cell lung cancer & 13.37 & 9.28 & 6.61 & 0.01 & $1.44(1.10-1.90)$ \\
\hline Squamous cell carcinoma & 28.49 & 20.48 & 13.08 & $<0.001$ & $1.39(1.17-1.65)$ \\
\hline Adenocarcinoma & 27.62 & 47.34 & 52.31 & $<0.001$ & $0.58(0.49-0.69)$ \\
\hline Large cell carcinoma & 20.93 & 5.15 & 158.81 & $<0.001$ & $4.07(3.27-5.06)$ \\
\hline Other types & 9.59 & 17.76 & 15.43 & $<0.001$ & $0.54(0.39-0.75)$ \\
\hline
\end{tabular}

${ }^{a}$ Data from the International Lung Cancer Consortium (133). GMLC, gastrointestinal metastases of lung cancer; RR, relative risk; 95\% CI, $95 \%$ confidence interval.

Table III. Association between GI complications, organ and histological types of gastrointestinal metastases of lung cancer.

\begin{tabular}{|c|c|c|c|c|c|c|c|}
\hline \multirow[b]{2}{*}{ Organ ${ }^{\mathrm{a}} /$ histological type $^{\mathrm{b}}$} & \multicolumn{2}{|c|}{ Perforation, n (\%) } & \multicolumn{2}{|c|}{ Hemorrhage, n (\%) } & \multicolumn{2}{|c|}{ Obstruction, n (\%) } & \multirow[b]{2}{*}{ Total } \\
\hline & Yes & No & Yes & No & Yes & No & \\
\hline Esophagus & $0(0.0)$ & $1(100.0)$ & $0(0.0)$ & $1(100.0)$ & $0(0.0)$ & $1(100.0)$ & 1 \\
\hline Stomach & $5(13.9)$ & $31(86.1)$ & $19(52.8)$ & $17(47.2)$ & $0(0.0)$ & $36(100.0)$ & 36 \\
\hline Small intestine & $135(63.7)$ & $77(36.3)$ & $33(15.6)$ & $179(84.4)$ & $43(20.3)$ & 169 (79.7) & 212 \\
\hline Colorectum & $10(11.5)$ & $77(88.5)$ & $28(32.2)$ & $59(67.8)$ & $18(20.7)$ & 69 (79.3) & 87 \\
\hline Multiple organs & $0(0.0)$ & $12(100.0)$ & $7(58.3)$ & $5(41.7)$ & $4(33.3)$ & $8(66.7)$ & 12 \\
\hline Unreported organ & $0(0.0)$ & $9(100.0)$ & $1(11.1)$ & $8(88.9)$ & $8(88.9)$ & $1(11.1)$ & 9 \\
\hline Squamous cell carcinoma & $49(50.5)$ & $48(49.5)$ & $20(20.6)$ & $77(79.4)$ & $20(20.6)$ & 77 (79.4) & 97 \\
\hline Adenocarcinoma & $33(35.5)$ & $60(64.5)$ & $23(24.7)$ & $70(75.3)$ & $16(17.2)$ & $77(82.8)$ & 93 \\
\hline Large cell carcinoma & $26(36.6)$ & $45(63.4)$ & $26(36.6)$ & $45(63.4)$ & $18(25.4)$ & $53(74.6)$ & 71 \\
\hline Small cell lung cancer & $24(53.3)$ & $21(46.7)$ & $8(17.8)$ & $37(82.2)$ & $6(13.3)$ & $39(86.7)$ & 45 \\
\hline Adenosquamous carcinoma & $3(60.0)$ & $2(40.0)$ & $0(0.0)$ & $5(100.0)$ & $2(40.0)$ & $3(60.0)$ & 5 \\
\hline Sarcomatoid carcinoma & $0(0.0)$ & $15(100.0)$ & $8(53.3)$ & 7 (46.7) & $5(33.3)$ & $10(66.7)$ & 15 \\
\hline Other types or unreported & $15(48.4)$ & $16(51.6)$ & $3(9.7)$ & $28(90.3)$ & $6(19.4)$ & $25(80.6)$ & 31 \\
\hline Total & $150(42.0)$ & $207(58.0)$ & $88(24.6)$ & $269(75.4)$ & $73(20.4)$ & $284(79.6)$ & $357^{\mathrm{c}}$ \\
\hline
\end{tabular}

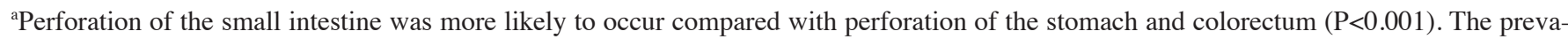
lence of hemorrhage descended in order of the stomach, colorectum and small intestine $(\mathrm{P}<0.05)$. Obstruction of the stomach was much less

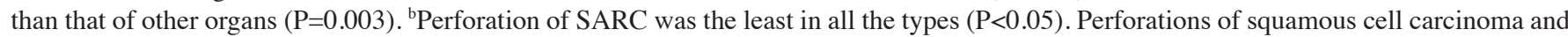
small cell lung cancer were more likely compared with adenocarcinoma $(\mathrm{P}<0.05)$. Hemorrhage of sarcomatoid carcinoma was more likely to happen compared with hemorrhage of squamous cell carcinoma $(\mathrm{P}=0.016)$, adenocarcinoma $(\mathrm{P}=0.049)$ and small cell lung cancer $(\mathrm{P}=0.018)$. Hemorrhage of large cell carcinoma was more likely to happen compared with hemorrhage of squamous cell carcinoma $(\mathrm{P}=0.022)$ and small cell lung cancer $(\mathrm{P}=0.030)$. No significant association was identified between histological type and gastrointestinal obstruction $(\mathrm{P}>0.05)$. ${ }^{\mathrm{C}}$ The complications in 9 cases were not reported.

histological type, GI perforation, extra-GI metastasis and abdominal surgery remained prognostic factors for survival rate. Other factors were not significant (Table V; Fig. 1B-D).

\section{Discussion}

As the digestive tract remains a rare site of metastasis of primary lung cancer, GMLC was previously described primarily in case reports (8). The clinical incidence of GMLC was $<2 \%$ in patients with primary lung cancer and $>10 \%$ in autopsy-associated studies (5-8). The majority of GMLC cases occurred at the end-stage of lung cancer, and misdiagnosis and missed diagnosis occurred frequently (138). In the present study, the sex and age of the patients with GMLC was similar with cases reported in previous studies with small sample sizes $(7,8)$. In the present study, the majority of the patients were elderly men.

The intestines, particularly the small intestine, were the main organs involved in GMLC, owing to their abundant blood supply. There were certain patients that presented with metastases in multiple GI organs, due to the lethality of the first involved organ and the involvement of additional GI organs. On account of the significant difference between the GMLC incidences from clinical and autopsy-associated studies, the majority of the patients with GMLC were subclinical with minimal or no symptoms. The symptoms of GMLC always appeared alongside clinical complications, including GI perforation, hemorrhage and obstruction. The incidence of severe 
Table IV. Association between gastrointestinal complications and chemotherapy.

\begin{tabular}{lccr}
\hline & \multicolumn{2}{c}{ Chemotherapy, n (\%) } & \\
\cline { 2 - 3 } Complications & Yes & No & P-value \\
\hline Perforation & & & 0.405 \\
Yes & $7(19.4)$ & $8(13.1)$ & \\
No & $29(80.6)$ & $53(86.9)$ & \\
Hemorrhage & & & $0.006^{\mathrm{a}}$ \\
Yes & $7(19.4)$ & $29(47.5)$ & \\
No & $29(80.6)$ & $32(52.5)$ & \\
Obstruction & & & 0.448 \\
Yes & $7(19.4)$ & $16(26.2)$ & \\
No & $29(80.6)$ & $45(73.8)$ & \\
Total ${ }^{\mathrm{b}}$ & 36 & 61 & \\
\hline
\end{tabular}

${ }^{a}$ Hemorrhages were less likely in patients who had received chemotherapy compared with patients who have not received chemotherapy $(\mathrm{P}=0.006) .{ }^{\mathrm{b}}$ Available data, 97 cases.

complications differed between organs due to differences in individual anatomical structures of the organs. Previous studies $(129,132,139)$ reported that the incidence of perforation in the small intestine was markedly increased compared with the incidence in the colorectum. The present study indicated similar findings. The probability and quantity of hemorrhage may depend on the incubation time of GMLC and the inner diameter of the involved organ. Metastases are able to grow for a longer period of time in the large gastric cavity, leading to more bleeding in the stomach compared with other organs. In the present study, no obstruction was identified in the stomach, and it was hypothesized that this may be associated with the wider inner diameter of the stomach compared with other GI organs.

In the present study, $>3 / 4$ of GMLC cases analyzed were squamous cell carcinoma, adenocarcinoma and large cell carcinoma. The high incidence of squamous cell carcinoma and adenocarcinoma was due to their high prevalence in primary lung cancer. The highest risk of GI metastasis was identified in large cell carcinoma, whereas the lowest risk of all the major histological types of GI metastasis was identified in adenocarcinoma. This finding is partly consistent with the autopsy data from Antler et al (6). On the other hand, different histological types of lung cancer exhibit different GI complications. A previous study on metastasis in the small intestine indicated that large cell carcinoma is associated with the greatest likelihood of perforation, whereas adenocarcinoma is most closely associated with the lowest rate of perforation in all the histological types (69). The present study partly confirmed this result and suggested that sarcomatoid carcinoma was associated with a lower rate of perforation and a greater rate of hemorrhages of the GI tract (Table III). This may be due to the relatively compact structure of sarcomatoid carcinoma with its differentiation of connective tissues. A number of previous studies $(112,140)$ have suggested that GI perforation may be caused by chemotherapy, but other studies $(106,141)$ indicated that GI perforation is brought about mainly by ischemia and necrosis of metastases, obstruction and high pressure in the GI cavity. In the present study, in which only a quarter of the total studies contained data on GI perforation, patients with or without chemotherapy experience statistically similar incidences of perforation and obstruction. The risk of hemorrhage may be decreased by chemotherapy, which may lead to tumor atrophy and ischemia.

The diagnosis of GMLC is not easy owing to its non-specific symptoms, although its complications are well known. When patients with lung cancer complain of potential GMLC symptoms (abdominal pain, nausea, vomiting, anemia, hematochezia, melena, constipation or other changes in bowel habits), particularly those that cannot be explained by primary lung cancer or undergoing chemotherapy or radiotherapy treatment, GMLC should be considered. As part of systemic metastases, GMLC is caused by hematogenous dissemination (8). In previous studies $(88,141), 42.9-100.0 \%$ of the patients with GMLC had extra-GI metastasis, and this ratio was $70.5 \%$ in the present study. Therefore, it is necessary for patients with GMLC to undergo sufficient evaluations prior to initiation of treatment (142). On the other hand, it was reported that GMLC was more common in patients with metastases in adrenal glands, kidneys and celiac lymph nodes compared with in patients with other type of metastases (5). However, this finding was not supported by the data in the present study.

Laboratory examination, endoscopy, gastroenterography, computed tomography (CT) and positron-emission tomography (PET)-CT may aid the diagnosis of GMLC (120). In a study by Kim et al (141) on the signs of GMLC in CT, it was reported that positive signs could be identified in $93 \%$ of patients, including localized GI wall thickening, the presence of a mass in the GI cavity, regional glandular enlargement, indigitation and perforation. PET-CT was able to assist the detection of subclinical GMLC and systemic evaluation of extra-GI metastases $(133,143,144)$. Pathology was a critical factor in diagnosis. The pathology of primary lung cancer should be reviewed and compared with that of GMLC. In the present study, in the majority of cases of GMLC considered, there was positive immunohistochemical staining for thyroid transcription factor 1 and cytokeratin-7 but negative staining for CK20 and CDX2, which was consistent with a previous study (8).

As the end-stage of lung cancer, GMLC was always associated with a poor prognosis (69). In the present study, the median OS time was 2.8 months and $53.4 \%$ of the patients succumbed to disease within 3 months of diagnosis of GMLC. Only $9.0 \%$ (24/268) of patients were reported to survive for $>1$ year and 2 patients $(0.7 \%)$ with large cell carcinoma survived $>7$ years. Patients in the dataset analyzed by the present study generally exhibited longer overall survival times compared with patients assessed by Garwood et al (69). The patients that Garwood et al (69) studied are part of the present dataset. All patients in the study by Garwood et al (69) exhibited perforation of the small intestine, which appears to be associated with shorter OS (based on comparisons between the results of the present study and Garwood et al) (69). In the present study, there were five factors, including region, histological type, GI perforation, extra-GI metastasis and surgical resection, which formed the final components included in the multivariate Cox 
Table V. Univariate and multivariate Cox regression analyses of variables that may affect overall survival of patients with gastrointestinal metastases of lung cancer.

A, Univariate analysis

Overall survival

Variable

HR

$95 \% \mathrm{CI}$

P-value

Demographic factors

Region

Asia

America

1.00

Europe

3.27

1.27

2.32-4.59

$<0.001$

Sex

Male

1.00

Female

0.81

$0.92-1.76$

0.148

Age, years

$\leq 54$

1.00

55-64

0.86

0.96

$0.60-1.25$

0.430

65-74

$0.66-1.42$

0.849

$\geq 75$

1.27

$0.78-2.07$

0.339

Histological type

Squamous cell carcinoma

1.00

Adenocarcinoma

0.78

$0.55-1.10$

0.150

Large cell carcinoma

0.75

$0.52-1.08$

0.123

Small cell lung cancer

0.62

0.41-0.96

0.031

Adenosquamous carcinoma

2.01

$0.73-5.56$

0.177

Sarcomatoid carcinoma

0.34

0.16-0.72

0.005

Time of GI metastasis

Synchronous

1.00

Metachronous

0.62

$0.43-0.90$

0.011

Number of GI metastasis

Solitary

1.00

Multiple

1.64

$0.98-2.76$

0.064

GI metastasis organ

Esophagus $^{a}$

N/A

Stomach

1.00

Small intestine

1.19

$0.82-1.73$

0.367

0.78

$0.48-1.28$

0.321

Multiple organs

0.95

0.44-2.05

0.886

Perforation

No

Yes

Extra-GI metastasis

No

Yes

Treatment factors

Surgical resection of the primary cancer

No

Yes

Abdominal surgery 
Table V. Continued.

B, Multivariate analysis

\section{Overall survival}

Variable

Adjusted HR

$95 \%$ CI

P-value

Demographic factors

Region

Asia

1.00

America

3.91

$2.41-6.34$

$<0.001$

Tumor factors

Histological type

Squamous cell carcinoma

1.00

Adenosquamous carcinoma

5.57

1.84-16.83

0.002

Perforation

No

1.00

Yes

Extra-GI metastasis

No

Yes

1.92

Treatment factors

Surgical resection

No

Yes

0.47

$0.28-0.81$

0.006

Other factors

${ }^{\text {a} E s o p h a g e a l ~ m e t a s t a s i s ~ i n ~} 1$ case. HR, hazard ratio; CI, confidence interval; GI, gastrointestinal; NS, not significant.
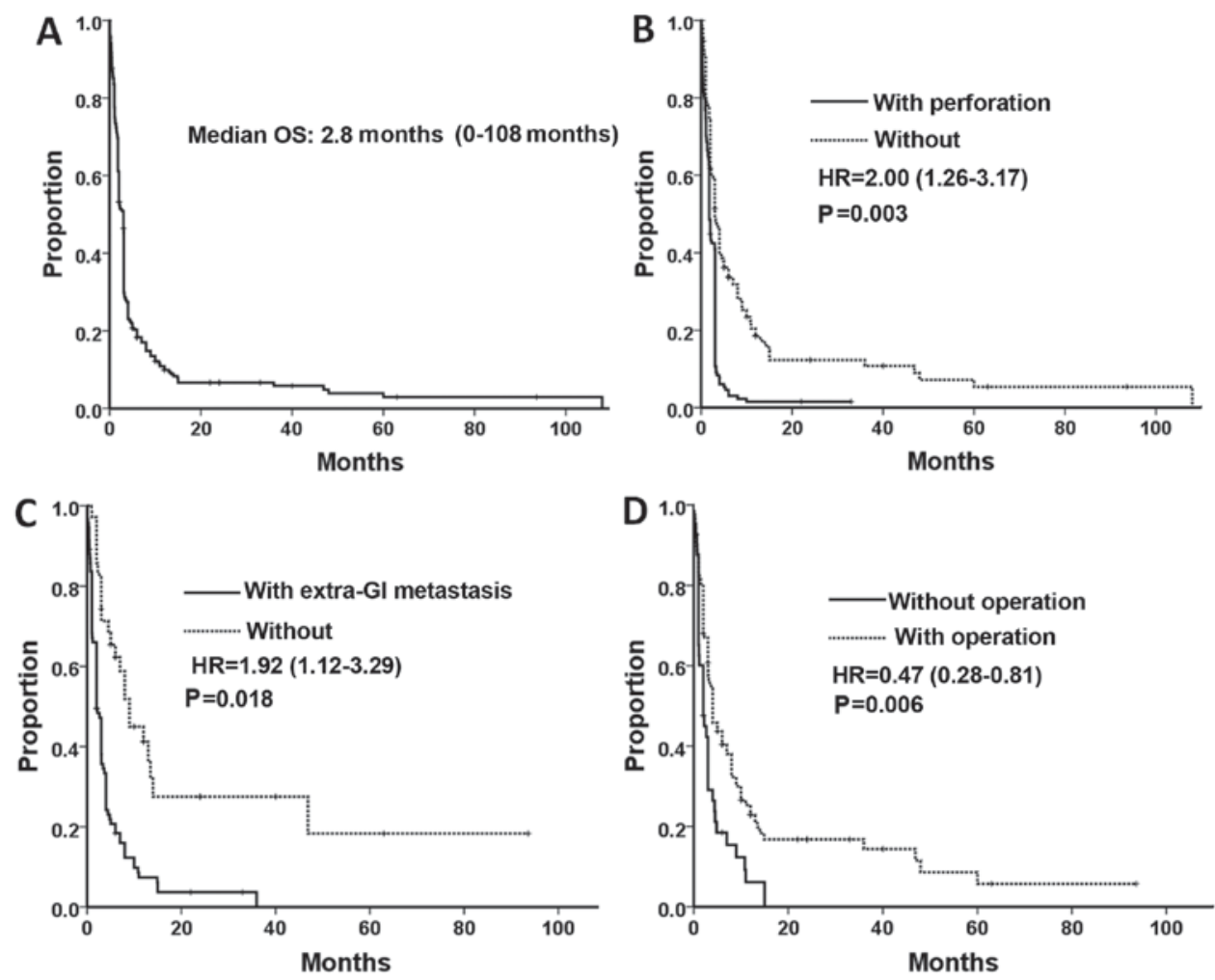

Figure 1. (A) OS of patients with gastrointestinal metastases of lung cancer. Variables affecting OS in multivariate Cox regression analysis: (B) Perforation, (C) extra-GI metastasis and (D) abdominal surgery. GI, gastrointestinal; HR, hazard ration; OS, overall survival. 
model. Although it was indicated that the survival times for Asian patients were longer compared with American patients, region was not a useful factor in determining survival times as American studies assessed in the present study were undertaken on average 20 years earlier compared with the studies from Asia. With an adjusted hazard ratio of $5.57(\mathrm{P}=0.002)$, it was indicated that patients with adenosquamous carcinoma had a significantly poorer prognosis compared with patients with squamous cell carcinoma based on multivariate Cox analysis. However, only four cases of adenosquamous carcinoma were available in the present survival analysis, so this result is of limited value. Perforation of GMLC and extra-GI metastasis were indicated to be negative prognostic factors, but abdominal surgery appeared to be a positive prognostic factor. However, the selective bias of the patients, particularly in treatment choice, must be considered in the present retrospective study. The patients with less severe general conditions were more likely to undergo surgery than those in critical conditions.

The present study revealed that, due to the increasing incidence of lung cancer, as well as the ability of modern medicine to prolong the life of lung cancer patients, GMLC is no longer rare. On the basis of the assessment performed in the present study, the histological distribution of GMLC was different from that of primary lung cancer. Early detection, diagnosis and treatment are central to improving patient prognosis. Sufficient and careful evaluations, targeted surgeries and systemic therapies for specific patients following discussion between multi-disciplinary teams of medics are able to improve the survival rate and quality of life of patients $(138,145)$. The main purpose of surgery is to relieve symptoms while causing the least trauma possible to the patient. Data from the present study revealed that $>30 \%$ of the patients had multiple metastases in their GI tract, therefore careful investigations during the surgery are required to avoid subclinical metastases being missed.

\section{Acknowledgements}

The present study was funded by grants from the Natural Science Foundation of Zhejiang Province of China (nos. LY14H160030 and LY13H160011), the National Program on Key Basic Research Project of China (973 Program; no. 2014CB542003), the National Natural Science Foundation of China (no. 30801341) and the Zheng Shu Elite Scholarship for Clinical Medicine.

\section{References}

1. Mao Y, Yang D, He J and Krasna MJ: Epidemiology of Lung Cancer. Surg Oncol Clin N Am 25: 439-445, 2016.

2. Chen W, Zheng R, Baade PD, Zhang S, Zeng H, Bray F, Jemal A, Yu XQ and He J: Cancer statistics in China, 2015. CA Cancer J Clin 66: 115-132, 2016.

3. Siegel RL, Miller KD and Jemal A: Cancer statistics, 2017. CA Cancer J Clin 67: 7-30, 2017.

4. Frank CD, Roy HD, Lynn T and Rogerio CL: Non-small Cell Lung Cancer. In: DeVita, Hellman and Rosenberg's Cancer: Principles \& Practice of Oncology. 10th Edition. Wolters Kluwer Health Corp., Philadelphia, pp 495-502, 2015.

5. Yoshimoto A, Kasahara K and Kawashima A: Gastrointestinal metastases from primary lung cancer. Eur J Cancer 42: 3157-3160, 2006.

6. Antler AS, Ough Y, Pitchumoni CS, Davidian M and Thelmo W: Gastrointestinal metastases from malignant tumors of the lung. Cancer 49: 170-172, 1982.
7. Yang CJ, Hwang JJ, Kang WY, Chong IW, Wang TH, Sheu CC, Tsai JR and Huang MS: Gastro-intestinal metastasis of primary lung carcinoma: clinical presentations and outcome. Lung Cancer 54: 319-323, 2006

8. Rossi G, Marchioni A, Romagnani E, Bertolini F, Longo L, Cavazza A and Barbieri F: Primary lung cancer presenting with gastrointestinal tract involvement: Clinicopathologic and immunohistochemical features in a series of 18 consecutive cases. J Thorac Oncol 2: 115-120, 2007.

9. Chongbo S and Gaojia Z: A case report of small intestinal metastasis of lung cancer. Chin J Clin Oncol 20: 319, 1993. (In Chinese)

10. Zhiqiang $\mathrm{C}$ and Chenghai $\mathrm{Z}$ : Lung cancer with its first symptom of gastrointestinal hemorrhage: a case report. J Jinan Univ (Med Ed) 17: 132, 1996. (In Chinese)

11. Yuyuan Y: Bowel obstruction caused by colonic metastasis of squamous cell lung cancer: a case report. Chin J Cancer 18: 143, 1999. (In Chinese)

12. Jianguo S, Xiufeng $Z$ and Qingmei J: A case report of rectal metastasis of small cell lung cancer. Chin J Cancer Prev Treat 7: 369, 2000. (In Chinese)

13. Jun Q, Wenyong S, Dechuan L, Rongcan L and Guiquan L: A case report of lung cancer with right colonic metastasis. J Coloproctol Surg 7: 49, 2001. (In Chinese)

14. Xiaoqiang L, Delong Z, Yimeng Z and Chunbao Z: Gastric metastasis of primary lung cancer: one case report. Suzhou Med 24: 160, 2001. (In Chinese)

15. Xiaoning $C$, Jinlong $C$ and Shilian Z: Bowel obstruction caused by ileum metastasis of lung cancer: a case report. Chin J Prim Med Pharm 9: 795, 2002. (In Chinese)

16. Xin T, Wang W, Xu Y, Yang Y, Hao W and Li Y: A case report of rectal metastasis of lung cancer. Zhongguo Fei Ai Za Zhi 5: 457, 2002. (In Chinese)

17. Jinlin L and Xiaoming L: Jejunal metastasis of lung cancer: one case report. J Abdom Surg 15: 59, 2002.

18. Hui C, Yaoguang L and Yin L: A case report of gastric metastasis of lung cancer. J Guangxi Med Univ 21: 766, 2004. (In Chinese)

19. Huili $Z$ and Hanmeng Y: Bowel idigitation caused by intestinal metastasis of lung cancer: one case report. Med J CASC 6: 35, 2004.

20. Yan L and Chongqin Y: Ileum metastasis of lung adenocarcinoma: a case report. Chin J Geriatr 24: 382-383, 2005.

21. Xiangtao M, Liwei Y, Jing F, Shan W, Ruyi D and Zhirong C: A case report of colonic metastasis of undifferentiated lung cancer. Chin J Clin Oncol 33: 358, 2006. (In Chinese)

22. Xiangtao M, Liwei Y, Jing F, Shan W, Ruyi D and Zhirong C: Colonic metastasis of squamous cell lung cancer: a case report and review. Cancer Res Prev Treat 33: 631, 2006.

23. Yong L, Yuguo H, Yongcan L, Hongzhe Y and Fengxia J: A case of colonic metastasis of lung cancer. Chin J Thorac Cardiovase Surg 23: 113, 2007.

24. Jianzhong D, Pin Z and Yi W: A case of multiple bowel perforations caused by jejunum metastasis of lung cancer. Chin $\mathrm{J}$ Surg 46: 77, 2008. (In Chinese)

25. Lixia L and Weimin Z: Small intestinal metastasis of lung cancer: a case report. J Prac Med 24: 3853, 2008.

26. Xuan W, He H, Muyan C, Liping L, Yuanyuan Z and Li Z: Small intestinal metastasis of non-small cell lung cancer: Case report and literature review. Chin J Cancer 27: 447-448, 2008. (In Chinese)

27. Wei H, Baojin $\mathrm{H}$ and Weiru X: A case report of gastric metastasis of primary lung cancer. Chin J Oncol 30: 698, 2008. (In Chinese)

28. Yingman W, Xiangmin L and Haixia Z: Small intestinal metastasis of lung cancer: case report and literature review. J Fourth Mil Med Univ 30: 96, 2009.

29. Qian L, JIangyang L, Xiaohong W, Yi Y and Lin L: Clinical and pathological analysis of lung giant cell carcinoma with neuroendocrine differentiation metastatic to small intestine. J Diag Pathol 16: 100-103, 2009.

30. Miao Z, Li R and Guangqin Z: A case of gastrointestinal haemorrhage caused by small intestinal metastasis of squamous cell lung cancer. Med J Chin PAPF 21: 605-606, 2010.

31. Fenghui Z and Yunping Z: A case of choroid membrane and rectal metastasis of lung cancer. Chin J Clin Oncol 37: 878 , 2010. (In Chinese)

32. Liu Y, Zhang L, Han X and Zhou T: A case report and literature review of small intestinal metastasis of large cell lung cancer. Zhongguo Fei Ai Za Zhi 13: 655-658, 2010 (In Chinese).

33. Zhidong L, Weijun Z, Funan L, Yimin D and Jixian S: Bowel perforation caused by colonic metastasis of small cell lung cancer: a case report. J Basic Clin Oncol 23: 451-452, 2010. 
34. Mo S, Lei D, Wei J, Bin Y and Hongjiang W: Bowel indigitation caused by small intestinal metastasis of lung cancer. J Dalian Med Univ 32: 374-375, 2010.

35. Lei Y, Xishan W, Xinshu D and Li L: Multiple small intestinal metastasis of lung cancer. Chin J Oncol 32: 525, 2010. (In Chinese)

36. Wang Y, An T, Yang L, Wang Z, Zhuo M, Duan J, Wang J and $\mathrm{Wu}$ M: Primary lung cancer with gastrointestinal metastasis: 2 case report and literature review. Zhongguo Fei Ai Za Zhi 14 278-280, 2011. (In Chinese)

37. Wu W, Mu J, Tong L and Liu Z: Primary lung squamous cell carcinoma ileocecal metastasis: one case report and literature review. Int J Respir 31: 1225-1227, 2011.

38. Xu L, Zijun L, Yahuan G and Juntao Y: Esophagus metastasis of mucoepidermoid lung carcinoma: case report and literature review. Cancer Res Prev Treat 38: 1462, 2011.

39. Hong Z, Xiaojing L and Honglin W: Duodenal metastases from primary squamous cell carcinoma of the lung: one case report. J Chin Oncol 18: 319-320, 2012. (In Chinese)

40. Junni C, Bo Y, Yanli Z, Jie L and Fen W: Gastric metastasis of primary lung cancer: one case report Guangdong Med J 33: 1369, 2012.

41. Pezzuto A, Mariotta S, Fioretti F and Uccini S: Metastasis to the colon from lung cancer presenting with severe hyponatremia and dyspnea in a young male: A case report and review of the literature. Oncol Lett 5: 1477-1480, 2013.

42. Huang YM, Hsieh TY, Chen JR, Chien HP, Chang PH, Wang CH and Huang JS: Gastric and colonic metastases from primary lung adenocarcinoma: A case report and review of the literature. Oncol Lett 4: 517-520, 2012.

43. Sakai H, Egi H, Hinoi T, Tokunaga M, Kawaguchi $Y$, Shinomura M, Adachi T, Arihiro K and Ohdan H: Primary lung cancer presenting with metastasis to the colon: A case report. World J Surg Oncol 10: 127, 2012.

44. Hsing CT, Kim HY, Lee JH, Han JS, Lee JH, Chang JS, Choi SR and Jeong JS: Gastrointestinal metastasis from a primary adenocarcinoma of the lung presenting with acute abdominal pain. Korean J Gastroenterol 59: 382-385, 2012.

45. Pratto D, Resial M, Wulfson A, Gennaro M, Brarda M and Schmidt A: Jejuno-jejunal intussusception as presentation of a primary lung carcinoma: a case report. Acta Gastroenterol Latinoam 42: 50-52, 2012 (In Chinese).

46. Cedres S, Mulet-Margalef N, Montero MA, Martinez P Martinez A and Felip E: Rectal metastases from squamous cell carcinoma: A case report and review of the literature. Case Rep Med 2012: 947524, 2012

47. Lee PC, Lo C, Lin MT, Liang JT and Lin BR: Role of surgical intervention in managing gastrointestinal metastases from lung cancer. World J Gastroenterol 17: 4314-4320, 2011.

48. Fujiwara A, Okami J, Tokunaga T, Maeda J, Higashiyama M and Kodama K: Surgical treatment for gastrointestinal metastasis of non-small-cell lung cancer after pulmonary resection. Gen Thorac Cardiovasc Surg 59: 748-752, 2011

49. Salemis NS, Nikou E, Liatsos C, Gakis C, Karagkiouzis G and Gourgiotis S: Small bowel perforation secondary to metastatic non-small cell lung cancer. A rare entity with a dismal prognosis. J Gastrointest Cancer 43: 391-395, 2012

50. Yamada H, Akahane T, Horiuchi A, Shimada R, Shibuya H, Hayama T, Nozawa K, Ishihara S, Matsuda K and Watanabe T: A case of lung squamous cell carcinoma with metastases to the duodenum and small intestine. Int Surg 96: 176-181, 2011

51. Ceretti AP, Goi G, Barabino M, De Nicola E, Strada D, Bislenghi G and Opocher E: Colonic metastasis from primary carcinoma of the lung. Case report. Ann Ital Chir 82: 229-232, 2011 (In Italian).

52. Bugiantella W, Cavazzoni E, Graziosi L, Valiani S, Franceschini MS and Donini A: Small bowel metastasis from lung cancer: A possible cause of acute abdomen. Case report and literature review. G Chir 32: 120-122, 2011.

53. Lin $\mathrm{HC}, \mathrm{Yu} \mathrm{CP}$, Lin HA and Lee HS: A case of lung cancer metastasized to the gastrointestinal anastomosis site where the primary gastric cancer was resected 17 years ago. Lung Cancer 72: 255-257, 2011.

54. Azevedo CR, Cezana L, Moraes ES, Begnami MD, Paiva Junior TF, Dettino AL and Fanelli MF: Synchronous thyroid and colon metastases from epidermoid carcinoma of the lung: Case report. Sao Paulo Med J 128: 371-374, 2010.

55. Trouillet N, Robert B, Charfi S, Bartoli E, Joly JP and Chatelain D: Gastric metastases. An endoscopic series of ten cases. Gastroenterol Clin Biol 34: 305-309, 2010

56. Guerin E, Gilbert O and Dequanter D: Acute abdomen: A rare presentation of lung cancer metastasis. Case Rep Med 2009: 903897, 2009
57. Koch B, Tannapfel A, Vieth M and Grun R: Gastric metastasis from small cell lung cancer. Pneumologie 63: 585-587, 2009 (In German).

58. Yun IS, Lee JY, Lee JS, Lee JY, Byun JM, Kim EJ, Park JY and Park JK: Jejunal intussusception with gastrointestinal bleeding caused by metastatic lung cancer. Korean J Gastroenterol 51: 377-380, 2008 (In Koren)

59. Aokage K, Yoshida J, Ishii G, Takahashi S, Sugito M, Nishimura M, Ochiai A and Nagai K: Long-term survival in two cases of resected gastric metastasis of pulmonary pleomorphic carcinoma. J Thorac Oncol 3: 796-799, 2008.

60. Kim MS, Kook EH, Ahn SH, Jeon SY, Yoon JH, Han MS, $\mathrm{Kim} \mathrm{CH}$ and Lee JC: Gastrointestinal metastasis of lung cancer with special emphasis on a long-term survivor after operation. J Cancer Res Clin Oncol 135: 297-301, 2009.

61. Goh BK, Yeo AW, Koong HN, Ooi LL and Wong WK: Laparotomy for acute complications of gastrointestinal metastases from lung cancer: Is it a worthwhile or futile effort? Surg Today 37: 370-374, 2007.

62. Kostakou C, Khaldi L, Flossos A, Kapsoritakis AN and Potamianos SP: Melena: A rare complication of duodenal metastases from primary carcinoma of the lung. World $\mathrm{J}$ Gastroenterol 13: 1282-1285, 2007.

63. Ohashi K, Kiura K, Takigawa N, Mizushima T, Ino H, Tabata M, Ueoka $\mathrm{H}$ and Tanimoto M: Successful treatment of a patient with gastric and duodenal metastases from large cell carcinoma of the lung with carboplatin and gemcitabine. Anticancer Res 26: 4695-4696, 2006.

64. Karamouzis MV, Linardou H, Papadopoulos G, Bousboukea E, Kanaloupiti D, Bitza M, Spourlis N and Bafaloukos D: Gastrointestinal solitary metastases from squamous cell lung cancer. Lung Cancer 55: 251-252, 2007.

65. Kanemoto K, Kurishima K, Ishikawa H, Shiotani S, Satoh H and Ohtsuka M: Small intestinal metastasis from small cell lung cancer. Intern Med 45: 967-970, 2006.

66. Casella G, Di Bella C, Cambareri AR, Buda CA, Corti G, Magri F, Crippa S and Baldini V: Gastric metastasis by lung small cell carcinoma. World J Gastroenterol 12: 4096-4097, 2006.

67. Altintas E, Sezgin O, Uyar B and Polat A: Acute upper gastrointestinal bleeding due to metastatic lung cancer: An unusual case. Yonsei Med J 47: 276-277, 2006.

68. Miyazaki K, Satoh H and Sekizawa K: Metastasis to appendix from lung adenocarcinoma. Int J Gastrointest Cancer 36: 59-60, 2005.

69. Garwood RA, Sawyer MD, Ledesma EJ, Foley E and Claridge JA: A case and review of bowel perforation secondary to metastatic lung cancer. Am Surg 71: 110-116, 2005.

70. Morgan MW, Sigel B and Wolcott MW: Perforation of a metastatic carcinoma of the jejunum after cancer chemotherapy. Surgery 49: 687-689, 1961

71. Tillotson PM and Douglas RG Jr: Metastatic tumor of the small intestine. Three cases presenting unusual clinical and roentgenographic findings. Am J Roentgenol Radium Ther Nucl Med 88: 702-706, 1962 .

72. Hayashi K, Masuoka S and Kitade F: A case report of perforation of intestinal metastasis of lung cancer. Nihon Geka Hokan 34: 816-819, 1965 (In Japanese).

73. Wootton DG, Morgan SC and Hughes RK: Perforation of a metastatic bronchogenic carcinoma to the jejunum. Ann Thorac Surg 3: 57-59, 1967

74. Wellmann KF, Chafiian Y and Edelman E: Small bowel perforation from solitary metastasis of clinically undetected pulmonary giant cell carcinoma. Am J Gastroenterol 51: 145-150, 1969.

75. Midell AI and Lochman DJ: An unusual metastatic manifestation of a primary bronchogenic carcinoma. Cancer 30: 806-809, 1972.

76. Inalsingh $\mathrm{CH}$, Hazra $\mathrm{T}$ and Prempree $\mathrm{T}$ : Unusual metastases from carcinoma of the lung. J Can Assoc Radiol 25: 242-244, 1974.

77. Ramanathan T, Skene-Smith H, Singh D and Sivanesan S: Small intestinal perforation due to secondaries from Bronchogenic carcinoma. Br J Dis Chest 70: 121-124, 1976

78. Winchester DP, Merrill JR, Victor TA and Scanlon EF: Small bowel perforation secondary to metastatic carcinoma of the lung. Cancer 40: 410-415, 1977.

79. Ejeckam GC, Abele R, Thomas J and Heringer R: Abdominal crisis due to metastasizing lung carcinoma to the small bowel. Can J Surg 22: 351-353, 1979.

80. Sternberg A, Giler S, Segal I, Shmuter Z and Kott I: Small bowel perforation as the presenting symptom of squamous cell carcinoma of the lung. Clin Oncol 6: 181-186, 1980 
81. Leidich RB and Rudolf LE: Small bowel perforation secondary to metastatic lung carcinoma. Ann Surg 193: 67-69, 1981.

82. Rosencrans DL: Small bowel perforation caused by metastatic lung carcinoma. Ann Surg 197: 120, 1983.

83. Hernandez Quero J, Zubieta Tabernero J, Martin Moreno A, Caballero Morales T, de la Higuera Torres-Puchol J, Miras Parra F and de la Higuera Rojas J: Pulmonary large-cell carcinoma with multiple metastases in the small intestine. Rev Clin Esp 165: 285-286, 1982.

84. Catrambone G, Pesce L, Mazza M and Iurilli L: Perforation of the small intestine secondary to metastasis of pulmonary carcinoma. Minerva Chir 38: 55-59, 1983.

85. Nicolosi A, Paderi R, Onnis P and Cafini D: Ileal perforation caused by metastasis of bronchogenic carcinoma. Minerva Chir 40: 567-570, 1985.

86. Quayle AR, Holt S and Clark RG: Jejunal perforation secondary to metastatic bronchogenic carcinoma. Postgrad Med J 61 $163-165,1985$.

87. Vesth N, Jensen KH and Karkov J: Perforating small intestinal metastasis from a primary lung tumor. Ugeskr Laeger 147: 3492, 1985

88. McNeill PM, Wagman LD and Neifeld JP: Small bowel metastases from primary carcinoma of the lung. Cancer 59 1486-1489, 1987.

89. Pang JA and King WK: Bowel haemorrhage and perforation from metastatic lung cancer. Report of three cases and a review of the literature. Aust NZJ Surg 57: 779-783, 1987.

90. Cavenaile JC, Blairon J and Limbosch JM: Jejunal perforation indicating the metastatic extension of a bronchial neoplasm. Acta Chir Belg 88: 155-157, 1988.

91. Hwang GS, Yeh PF, Lee YC, Perng RP and Li WY: Small bowel perforation secondary to metastatic carcinoma of lung. Zhonghua Yi Xue Za Zhi (Taipei) 41: 159-164, 1988 (In Chinese).

92. Koury HI and Kenady D: Perforation of a metastatic lung adenocarcinoma of the jejunum. Am J Gastroenterol 83: 462-463, 1988.

93. Shatikhin VA, Vasil'ev AV and Bychkov MB: Metastasis of lung cancer to the small intestine with its perforation. Klin Med (Mosk) 66: 135-136, 1988

94. Shirani J and Brackett JW: Lung cancer presenting as small bowel perforation. Conn Med 53: 455-456, 1989.

95. Joyce WP, Huddy SP, Corbishley C and Wright NL: Small bowel complications of metastatic lung carcinoma. Ir J Med Sci 159: $149-150,1990$

96. Woods JM IV and Koretz MJ: Emergency abdominal surgery for complications of metastatic lung carcinoma. Arch Surg 125: $583-585,1990$.

97. Nakano Y, Kamimori T, Shoji S, Taruya E and Tanaka I: A case of jejunal metastasis from pulmonary adenocarcinoma occurring as perforative peritonitis. Nihon Kyobu Shikkan Gakkai Zasshi 29: 649-653, 1991 (In Japanese).

98. Yasunaga A, Shibata O, Sasaki T, Tohara K, Hadama T, Uchida Y, Yasunaga T and Adachi Y: A case of perforation of the metastatic site of lung carcinoma in the small bowel. Kyobu Geka 44: 596-599, 1991 (In Japanese).

99. Beluffi L, Agostini M, Ruck F, Valenghi D, Morotti L and Marsetti M: Peritonitis caused by jejunal perforation resulting from metastasis of pulmonary carcinoma. Minerva Chir 47: 1023-1026, 1992 (In Italian)

100. Gitt SM, Flint P, Fredell CH and Schmitz GL: Bowel perforation due to metastatic lung cancer. J Surg Oncol 51: 287-291, 1992.

101. Ryo H, Sakai H, Ikeda T, Hibino S, Goto I, Yoneda S and Noguchi Y: Gastrointestinal metastasis from lung cancer. Nihon Kyobu Shikkan Gakkai Zasshi 34: 968-972, 1996 (In Japanese).

102. Cossavella D, Paino O, Realis Luc A, Clerico G, Catania S, Pozzo M and Trompetto M: A rare form of intestinal perforation: adenocarcinoma of the ileum. Presentation of a clinical case. Minerva Chir 53: 431-433, 1998 (In Italian).

103. Fischer M, Papp J, Kulka J, Zsiray M, Kempler P and Szalay F: Upper gastrointestinal bleeding and intestinal perforation due to multiple duodenojejunal metastases from a silent bronchogenic adenosquamous carcinoma. Endoscopy 30: S79, 1998.

104. Shiraishi Y, Nakajima Y, Katsuragi N, Hanaoka T, Konno H and Tanaka S: Metastatic lung tumor: report of two cases. Kyobu Geka 56: 47-50, 2003.

105. Yokota T, Yamada Y, Sakata N, Kikuchi S, Kunii Y, Tezuka F, Suzuki H and Yamauchi H: Emergency abdominal surgery for small bowel perforation secondary to metastatic lung cancer. Tohoku J Exp Med 188: 265-270, 1999.
106. Ise N, Kotanagi H, Morii M, Yasui O, Ito M, Koyama K and Sageshima M: Small bowel perforation caused by metastasis from an extra-abdominal malignancy: Report of three cases. Surg Today 31: 358-362, 2001.

107. Polak M, Kupryjańczyk J and Rell KW: A rare case of colonic perforation in a sole site of latent lung cancer metastasis. Pol Tyg Lek 45: 179-181, 1990 (In Polish).

108. Rahman R, Bernstein Z, Vaickus L, Penetrante R, Arbuck S, Kopec I, Vesper D, Douglass HO Jr and Foon KA: Unusual gastrointestinal complications of interleukin-2 therapy. J Immunother (1991) 10: 221-225, 1991.

109. Fletcher MS: Gastric perforation secondary to metastatic carcinoma of the lung: a case report. Cancer 46: 1879-1882, 1980

110. Schmidt G, Börsch G, von Liebe S and Böhm E: Gastric perforation secondary to metastatic bronchogenic carcinoma. Hepatogastroenterology 32: 103-105, 1985.

111. Opanasenko NS: Gastric perforation into the left pleural cavity after pleuropulmonectomy for pulmonary cancer. Klin Khir: 56-57, 2000 (In Russian)

112. Suzaki N, Hiraki A, Ueoka H, Aoe M, Takigawa N, Kishino T, Kiura K, Kanehiro A, Tanimoto M and Harada M: Gastric perforation due to metastasis from adenocarcinoma of the lung. Anticancer Res 22: 1209-1212, 2002.

113. Sanli Y, Adalet I, Turkmen C, Kapran Y, Tamam M and Cantez S: Small bowel metastases from primary carcinoma of the lung: Presenting with gastrointestinal hemorrhage. Ann Nucl Med 19: 161-163, 2005.

114. Tomas D, Ledinsky M, Belicza M and Kruslin B: Multiple metastases to the small bowel from large cell bronchial carcinomas. World J Gastroenterol 11: 1399-1402, 2005.

115. Misra SP, Dwivedi M, Misra V, Dharmani S and Gupta M: Duodenal metastases from squamous cell carcinoma of the lung: Endoscopic management of bleeding and biliary and duodenal obstruction. Indian J Gastroenterol 23: 185-186, 2004.

116. Katsinelos P, Paroutoglou G, Beltsis A, Pilpilidis I, Papaziogas B, Mimidis K and Tsolkas P: Hematemesis as a presenting symptom of lung cancer with synchronous metastases to the esophagus and stomach. A case report. Rom J Gastroenterol 13: 251-253, 2004.

117. Kobayashi O, Murakami H, Yoshida T, Cho H, Yoshikawa T, Tsuburaya A, Sairenji M, Motohashi H, Sugiyama Y and Kameda Y: Clinical diagnosis of metastatic gastric tumors: Clinicopathologic findings and prognosis of nine patients in a single cancer center. World J Surg 28: 548-551, 2004.

118. Capasso L, Iarrobino G, D' Ambrosio R, Carfora E, Ventriglia R and Borsi E: Surgical complications for gastric and small bowel metastases due to primary lung carcinoma. Minerva Chir 59: 397-403, 2004.

119. Renault PA, Arotçarena R, Calès V, Lippa A, Benichou M, Laurent $\mathrm{P}$ and Laborde Y: Metastatic obstruction of the small bowel revealing or complicating squamous-cell lung cancer. Two cases and a review of the literature. Rev Pneumol Clin 59: $161-165,2003$

120. Yamamoto M, Matsuzaki K, Kusumoto H, Uchida H, Mine H, Kabashima A, Maehara Y and Sugimachi K: Gastric metastasis from lung carcinoma. Case report. Hepatogastroenterology 49: 363-365, 2002

121. Ito Y, Suzuki M, Oyamada Y, Kou H, Takeshita K, Asano K and Yamaguchi K: A case of relapsed small cell lung cancer recognized by simple metastasis to the duodenum. Nihon Kokyuki Gakkai Zasshi 39: 30-34, 2001 (In Japanese).

122. Fukata T, Fukino S, Hayashi E, Okada K, Tamai N and Nakashima H: A case of G-CSF-producing large cell carcinoma of the lung with gastric metastasis. Kyobu Geka 53: 798-803, 2000 (In Japanese).

123. Berger A, Cellier C, Daniel C, Kron C, Riquet M, Barbier JP, Cugnenc PH and Landi B: Small bowel metastases from primary carcinoma of the lung: clinical findings and outcome. Am J Gastroenterol 94: 1884-1887, 1999.

124. Centeno Cortés C, Borau Clavero MJ, Sanz Rubiales A and López-Lara Martín F: Intestinal bleeding in disseminated non-small cell lung cancer. Lung Cancer 18: 101-105, 1997.

125. Akahoshi K, Chijiiwa Y, Hirota I, Ohogushi O, Motomatsu T, Nawata $\mathrm{H}$ and Sasaki I: Metastatic large-cell lung carcinoma presenting as gastrointestinal hemorrhage. Acta Gastroenterol Belg 59: 217-219, 1996.

126. Raijman I: Duodenal metastases from lung cancer. Endoscopy 26: 752-753, 1994.

127. Gateley CA, Lewis WG and Sturdy DE: Massive lower gastrointestinal haemorrhage secondary to metastatic squamous cell carcinoma of the lung. Br J Clin Pract 47: 276-277, 1993. 
128. Maeda J, Miyake M, Tokita K, Iwahashi N, Nakano T, Tamura S, Hada T and Higashino K: Small cell lung cancer with extensive cutaneous and gastric metastases. Intern Med 31: 1325-1328, 1992.

129. Mosier DM, Bloch RS, Cunningham PL and Dorman SA: Small bowel metastases from primary lung carcinoma: A rarity waiting to be found? Am Surg 58: 677-682, 1992.

130. Park SW, Cho HJ, Choo WS, Chung KS, Kim HY, Yoo JY, Kim JS and Shin HS: A case of intestinal hemorrhage due to small intestinal metastases from primary lung cancer. Korean J Intern Med 6: 79-84, 1991.

131. Spedini C, Lombardi C and Buffoli F: Multiple mucosal gastrointestinal metastases from primary asymptomatic bronchogenic carcinoma. Recenti Prog Med 81: 442-444, 1990.

132. Ono H, Okabe M, Kimura T, Kawakami M, Nakamura K, Danjo Y, Takasugi $\mathrm{H}$ and Nishihara $\mathrm{H}$ : Colonic metastasis from primary carcinoma of the lung: Report of a case and review of Japanese literature. Clin J Gastroenterol 2: 89-95, 2009.

133. Stinchcombe TE, Socinski MA, Gangarosa LM and Khandani AH: Lung cancer presenting with a solitary colon metastasis detected on positron emission tomography scan. J Clin Oncol 24: 4939-4940, 2006.

134. Travis WD, Brambilla E, Nicholson AG, Yatabe Y, Austin JH, Beasley MB, Chirieac LR, Dacic S, Duhig E, Flieder DB, et al: The 2015 World Health Organization classification of lung tumors: impact of genetic, clinical and radiologic advances since the 2004 classification. J Thorac Oncol 10: 1243-1260, 2015.

135. Edge S, Byrd D, Compton C, Fritz A, Greene F and Trotti A: AJCC Cancer Stageing Manual. Springer, New York, 2010.

136. Kim CH, Lee YC, Hung RJ, McNallan SR, Cote ML, Lim WY, Chang SC, Kim JH, Ugolini D, Chen Y, et al: Exposure to secondhand tobacco smoke and lung cancer by histological type: A pooled analysis of the International Lung Cancer Consortium (ILCCO). Int J Cancer 135: 1918-1930, 2014.
137. Cox D and Oakes N: Analysis of Survival Data. Chapman and Hall, New York, 1984.

138. Guo Z, Han B and Wang Y: The status of diagnosis and therapy for gastrointestinal metastasis from primary lung cancer. Zhongguo Fei Ai Za Zhi 14: 69-71, 2011 (In Chinese).

139. Hillenbrand A, Sträter J and Henne-Bruns D: Frequency, symptoms and outcome of intestinal metastases of bronchopulmonary cancer. Case report and review of the literature. Int Semin Surg Oncol 2: 13, 2005

140. Yuen JS, Chow PK and Ahmed Q: Metastatic lung cancer causing bowel perforations: Spontaneous or chemotherapy-related? ANZ J Surg 72: 245-246, 2002.

141. Kim SY, Ha HK, Park SW, Kang J, Kim KW, Lee SS, Park SH and Kim AY: Gastrointestinal metastasis from primary lung cancer: CT findings and clinicopathologic features. AJR Am J Roentgenol 193: W197-W201, 2009.

142. Di JZ, Peng JY and Wang ZG: Prevalence, clinicopathological characteristics, treatment, and prognosis of intestinal metastasis of primary lung cancer: A comprehensive review. Surg Oncol 23: 72-80, 2014

143. Israel O, Yefremov N, Bar-Shalom R, Kagana O, Frenkel A, Keidar Z and Fischer D: PET/CT detection of unexpected gastrointestinal foci of 18F-FDG uptake: Incidence, localization patterns and clinical significance. J Nucl Med 46: 758-762, 2005.

144. Kim MS, Cheon GJ, Lim SM, Kim CH and Lee JC: F-18 FDG PET-CT imaging of intestinal metastasis from primary lung cancer. Clin Nucl Med 33: 870-871, 2008.

145. Kini S, Kapadia RM and Amarapurkar A: Intussusception due to intestinal metastasis from lung cancer. Indian J Pathol Microbiol 53: 141-143, 2010.

cc) (7) $\Theta$ This work is licensed under a Creative Commons (c) ${ }_{\text {EY NO ND }}$ Attribution-NonCommercial-NoDerivatives 4.0 International (CC BY-NC-ND 4.0) License. 